\title{
The possible protective effect of black seed (Nigella Sativa) oil on the testes of adult male albino rat exposed to noise
}

\author{
Amany Fekry Mohamed ${ }^{1 *}$, Safaa Masoud Hanafy ${ }^{1}$ and Ahmed Mahmoud ${ }^{2}$ \\ *Correspondence: dr_mokarrab@yahoo.com

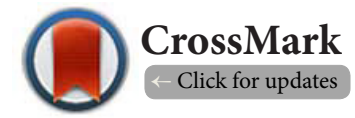

'Lecturer of Anatomy Department, Al -Azhar University, Egypt.

${ }^{2}$ Lecturer of Audiology Unit, Al-Azhar University, Egypt.

\begin{abstract}
The aim of this study is to investigate the effect of noise exposure on the histological structure of the adult male albino rat testes and evaluate the possible protective role of black seed (Nigella Sativa) oil on the histological structure of the adult male albino rat testes exposed to noise. This study was conducted to determine the injurious effects of noise on the testis and to show whether black seed oil has any modulatory effect on testicular injury. 40 adult male albino rats were divided into 4 groups. Group A (control group) was kept in an environment free from noise as control group. Group B was exposed to $95 \mathrm{~dB}$ of noise for 4 hours daily for duration of 45 days. Group $\mathrm{C}$ was exposed to $95 \mathrm{~dB}$ of noise for 4 hours daily for duration of 45 days and given orally black seed oil ( $5 \mathrm{ml} / \mathrm{kg}$ /day) during the period of noise exposure.Group D was kept in an environment free from noise and given orally black seed oil ( $5 \mathrm{ml} / \mathrm{kg} /$ day) for duration of 45days. Histological study was performed on the testes using light microscopy and Transmission electron microscopy (TEM). Morphometric study was done to measure the height of the spermatogenic cells. The result of the experiment revealed that the spermatogenic cells of group B appeared distorted. Most of the spermatogenic cells had vacuolated cytoplasm. Some of them had degenerated mitochondria and abnormal nuclei. Most of sperms were markedly affected. Their detailed structures couldn't be recognized. Group C showed preservation of the structure of the testes as compared to group B i.e., the spermatogenic cells became easily recognized and were arranged in rows along the basal lamina of the seminiferous tubules. They showed that most of the cytoplasmic vacuolations became absent but some mitochondria showed degeneration. Most of the nuclei of spermatogenic cells appeared similar to group A. There was significant decrease in the height of the spermatogenic cells in group B as compared to group A. In view of these findings, these data strongly suggest that noise stress had adverse effects on the testis of male albino rats. The administration of black seed oil protected the testis against the injurious effect of noise. The probable mechanism and usefulness of black seed oil in reducing the previously mentioned effects were possibly due to its antioxidant effects.
\end{abstract}

Keywords: Nigella Sativa, noise, testes, albino rat

\section{Introduction}

Noise stress is dangerous natural contaminant that produces harmful physiological, psychological and morphological outcomes to the body [1]. It is estimated that more than 600 million people in the world are exposed to extreme noise in their workplace. Noise is capable of causing impairment, behavioral, mental and widespread disturbances at several levels in human organs and apparatus due to chemical and physiological modification of endocrine, cardiovascular and nervous systems $[2,3]$. The effects of noise on lipid peroxidation and blood antioxidant enzymes of textile workers who were exposed to severe noise levels (105 Db) for eight hours per day are investigated and the findings indicate that severe noise creates oxidative stress [4]. The results of another study indicate that noise of $90 \mathrm{~dB}$ intensity can decrease sperm parameters and severe noise may affect fertility levels [5]. The status of oxidant and antioxidant parameters in blood and liver tissue of rats exposed to noise is explored and is showed that exposure to noise is toxic to blood and liver tissue [6]. Long-term exposure of Wistar rats to noise for different intensities (70 and $85 \mathrm{~dB}$ ) results in increased corticosterone levels, also it affects various parameters of the endocrine glands and cardiac function [7].

Despite the use of modern medicine, markets complementary and alternative medicines have become very demanding [8]. The

(C) 2015 Mohamed et al; licensee Herbert Publications Ltd. This is an Open Access article distributed under the terms of Creative Commons Attribution License (http://creativecommons.org/licenses/by/3.0). This permits unrestricted use, distribution, and reproduction in any medium, provided the original work is properly cited. 
Nigella Sativa (NS) plant, commonly known as "black seed", is used as a medicinal plant for the treatment of many diseases [9]. Thymoquinone, the active constituent of NS seeds is a pharmacologically active quinone which serves as an analgesic and anti-inflammatory agent [10]. In addition, thymoquinone may acts as an antioxidant agent and prevents membrane lipid peroxidation in tissues [11]. It has been shown that NS has protective effect against ischemia reperfusion injury to various organs [12]. Oral administration of NS seed oil can decrease the disease scores in patients with bronchial asthma and atopic eczema [13]. NS has also been shown to have antigenotoxicity and antibiotic properties as experimented on a variety of biological species [14].

There has been no research-up to our knowledge- that proved protective effect of NS seed oil administration against testis involvement due to noise exposure. The aim of this work is to explore the effects of noise exposure on the adult male albino rat testis and also to investigate the efficacy of black seed (NS) oil in protection against these effects.

\section{Material and methods Material \\ Animal}

In this study, 40 adult male albino rats weighing $200 \pm 20 \mathrm{~g}$ were used. Throughout the experiment, all animals were housed in the animal house of faculty of medicine, Al- Azhar University. They are observed and maintained on balanced diet and water. They were divided equally into four groups as follows. Group A was kept in an environment free from noise as control group. Group B was exposed to $95 \mathrm{~dB}$ of noise for 4 hours daily/45 days. Group C was exposed to $95 \mathrm{~dB}$ of noise for 4 hours daily $/ 45$ days and given orally black seed oil during the period of noise exposure at a dose of $5 \mathrm{ml} / \mathrm{kg}$ body weight daily. Group $D$ was kept in an environment free from noise and given black seed oil at a dose of $5 \mathrm{ml} / \mathrm{kg}$ body weight daily for 45 days.

\section{Noise exposure}

When noise stress of any kind exceeds $90 \mathrm{~dB}$, noise becomes a stressor [15]. Rats of group $B$ and $C$ were exposed to broadband noise $(95 \mathrm{~dB}) 4$ hours/day for 45 days. Noise was delivered to the rats through computer with two loud speakers connected to it. The distance between loud speakers and the center of the cages was $40 \mathrm{~cm}$. The dimensions of the cages were 30 $\mathrm{cm}$ length, $40 \mathrm{~cm}$ width and $15 \mathrm{~cm}$ height. Noise level was set at intensity of $95 \mathrm{~dB}$ uniformly throughout the cage. Noise intensity was measured at different points inside the cage using calibrated B\&K sound level meter device type 2235 and regularly monitored.

\section{Black seed (Nigella Sativa) oil}

NS oil (pure product extracted coldly) was purchased from Zamzam Company for extracting natural oils, herbs and cosmetics, under license of Ministry of Health, Cairo, Egypt. NS oil was administered at a dose of $5 \mathrm{ml} / \mathrm{kg}$ body weight daily $[16,17]$ orally for 45 days during noise exposure.

\section{Methods \\ Histological study:using \\ Light microscopy}

The rats were anaesthetized lightly by diethyl ether inhalation and the abdominal cavity was exposed by midline incision. The testes were removed and fixed. The specimens were fixed by immersion in Bouin's solution for 3days. The specimen were dehydrated in ascending grades of ethyl alcohol and cleared in benzene. The specimens were impregnated for three changes in paraffin and were finally embedded in paraffin wax. The paraffin blocks were cut by rotary microtome into serial transverse sections at 8um - thick. Every five successive transverse paraffin sections were attached to an albumenized glass slides. The following stains were used for this work: 1Haematoxylin and Eosin stain [18] which was used for study of the general structure. 2- Masson's Trichrome stain [18] was used to demonstrate collagen fibers. 3- Periodic acid Schiff's reaction (PAS) technique [19] which was used for the study of mucopolysaccharides and polysaccharides.

\section{Transmission electron microscopy (TEM)}

The testis was extracted. Samples were fixed $5 \%$ glutaraldehyde in $0.1 \mathrm{M}$ in sodium cacodylate buffer at 7.3. The specimen then post-fixed with a $1 \%$ osmium tetroxide in the same cacodylate buffer;the specimens were then dehydrated, cleared and embedded in epoxy resin [20]. Ultrathin sections (60a $\mathrm{nm}$ ) were cutand examined using a transmission electron microscope (JEOL1010 EX II, Japan) at the Regional Mycology and Biotechnology center, Al-Azhar University, Cairo, Egypt.

\section{Morphometric analysis}

Morphometric measurements were performed by using (Leica Qwin 500c) image analyzer computer system (England) at the Regional Mycology and Biotechnology center, Al-Azhar University, Cairo, Egypt. The image analyzer was used to measure the height of germinal epithelium in the seminiferous tubules of the studied groups. Four slides stained with haematoxylin and eosin was taken from five equidistant points along each serially sectioned specimen. Then five seminiferous tubules were randomly selected in each slide to measure the height of germinal epithelium. Measuring the height was done by taking seven different heights for each seminiferous tubule at magnification $\times 100$ in astandard frame $50 \mathrm{um} 2$. The mean height of germinal epithelium of each seminiferous tubule was calculated. The cumulative mean height for each group was calculated statistically. The data was subjected to statistical analysis.

\section{Statistical analysis}

The results were collected, tabulated, statistically analyzed and represented graphically. The data were subjected statistically 
Mohamed et al. Journal of Histology \& Histopathology 2015,

http://www.hoajonline.com/journals/pdf/2055-091X-2-21.pdf

to one way analysis of variance (ANOVA). When the results of ANOVA test was significant, comparisons between pairs of groups were done using Post Hoc Tukey's test to know which group is different from each other [21].

\section{Results}

Histological examination of the testes of group A and group $D$ revealed no difference, so they were pooled together.

\section{Group A}

Light microscopic examination of transverse sections of testes of group A showed that the testicular capsule was thin and regular. The seminiferous tubules were rounded and regular (Figure 1A). The seminiferous tubules were surrounded by regular thin basal lamina. They were separated by the interstitial cells of leydig. Normal architecture of the spermatogenic cells (Sertoli cells, Spermatogonia A, Spermatogonia B, primary spermatocytes, early spermatids, late spermatids and spermatozoa) at various stages of development was observed (Figure 2A). Sections stained with Masson's trichrome stain showed normal distribution of collagen fibers in the capsule and in the

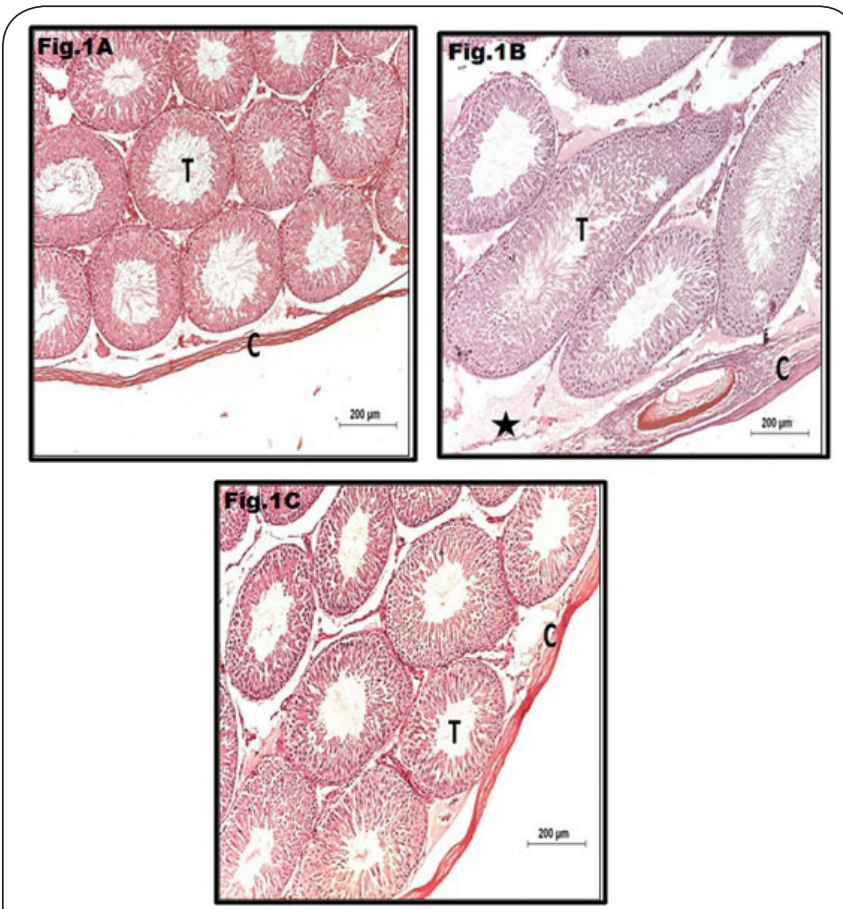

Figure 1. (A) A photomicrograph of transverse section adult albino rat testis of group A showing normal architecture of the capsule (C) and the seminiferous tubules (T). (B) A photomicrograph of transverse section adult albino rat testis of group B showing that the capsule $(\mathrm{C})$ is thick with congested dilated blood vessels. The space between the seminiferous tubules contains eosinophilic material (star).

(C) A photomicrograph of transverse section testis of adult albino rat of group $C$ showing that the capsule $(C)$ and the seminiferous tubules $(\mathrm{T})$ are more or less similar to that of the group A.
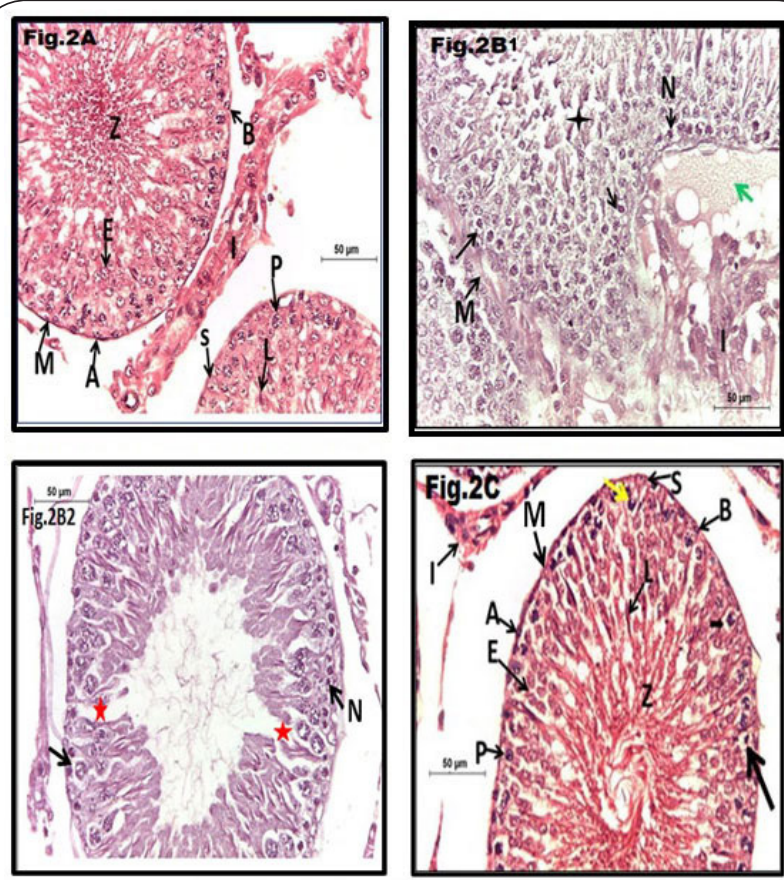

Figure 2. (A) A photomicrograph of transverse section of adult albino rat testis of group A showing spermatogonia $A$ $(A)$ and $B(B)$ rest on defined basal lamina(M). Notice the presence of primary spermatocyte(P), early spermatid(E), late spermatid(L) and sertoli cells $(\mathrm{S})$, spermatozoa $(\mathrm{z})$. The interstitial cells of leydig (I) appear between the seminiferous tubules. (B1) A photomicrograph of transverse section of testis of adult albino rat of group B showing marked deterioration of the seminiferous tubule. The basal lamina (M) of seminiferous tubules appears distorted and detached. Most of spermatogenic cells have vacuolated cytoplasm (black arrow). Some of their nuclei (N) appear deeply stained and irregular. Notice the presence of intercellular space (star) between the spermatogenic cells. Notice also the presence of eosinophilic material between the seminiferous tubules (green arrow). The interstitial cell of leydig (I)appears dispersed. (B2)A photomicrograph of transverse section of testis of adult albino rat of group B showing that most of spermatogenic cells have vacuolated cytoplasm (black arrow). Some of their nuclei appear deeply stained and irregular $(\mathrm{N})$. Notice the presence of intercellular space (red star) between the spermatogenic cells. Notice also the absence of sperms in the lumen of the seminiferous tubules.

(C) A photomicrograph of transverse section of testis of adult albino rat of group $\mathrm{C}$ showing mild deterioration of seminiferous tubules. The basal lamina $(\mathrm{M})$ appears continuous and regular. Most of the spermatogonia $A(A)$, spermatogonia B (B), Sertoli cells (S), primary spermatocytes $(\mathrm{P})$, early spermatid(E) and late spermatid (L) are more or less similar to that of group A. Some spermatogenic cells have vacuolated cytoplasm(black arrow) while few of them have deeply stained nucleus(yellow arrow). The interstial cells of leydig (I) appear nearly similar to that of group A.

basal lamina of seminiferous tubules (Figure 3A). Sections stained with Periodic Acid Schiff's stain (PAS) showed normal PAS positive reaction in the capsule, basal lamina and in the 

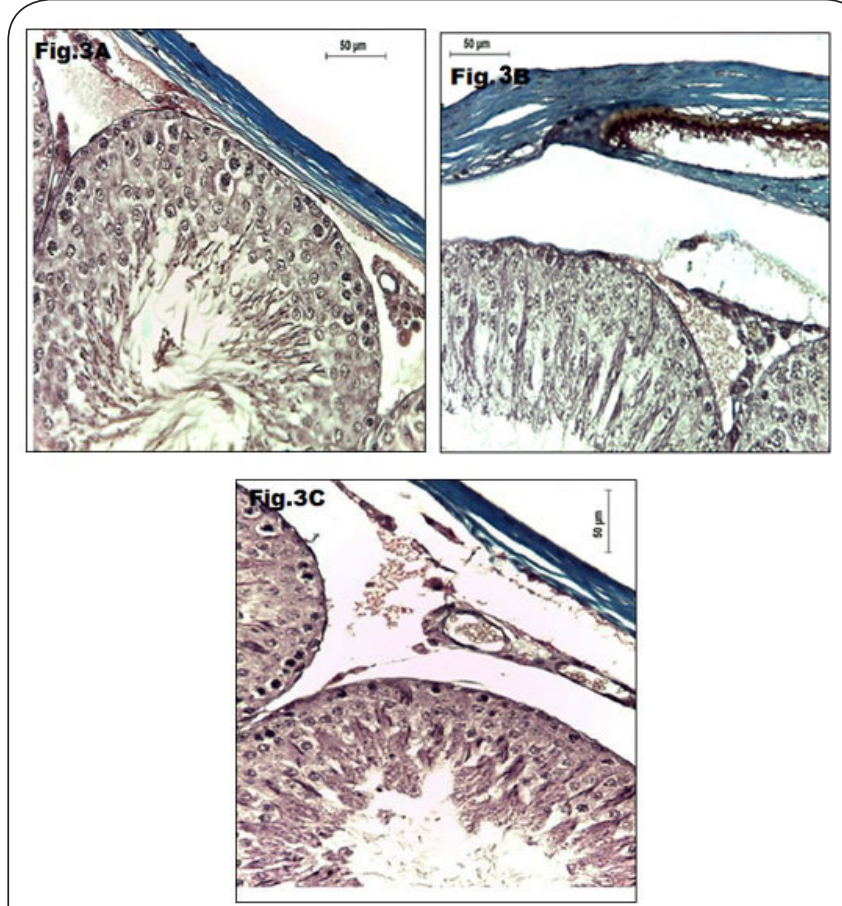

Figure 3. (A) A photomicrograph of transverse section of control adult albino rat testis showing normal distribution of collagen fibers in the capsule, blood vessels and basal lamina of seminiferous tubules.

(B) A photomicrograph of transverse section of testis of adult albino rat of group B showing marked increase in collagen fiber deposition in the capsule, blood vessels and basal lamina of seminiferous tubules.

(C) A photomicrograph of transverse section of testis of adult albino rat of group $\mathrm{C}$ showing that the distribution of collagen fiber appears nearly similar to the group A.

spermatogenic cells (Figure 4A).

Ultrastructure examination of the testes of group A showed that the basal lamina of the seminiferous tubule (Figure 5A) consisted of basement membrane and two cellular layers; inner or myoid and outer or fibroblast layers. The basement membrane enclosed the seminiferous tubule. It was separated from the inner cellular layer by gap containing collagen fibers. The outer cellular layer was separated from the inner layer by small gap in which collagen fibers were few. Sertoli cells were seen resting on the basement membrane of the seminiferous tubule. These cells characterized by infolding of their pyramidal euchromatic nuclei. Spermatogonia A had wide area of contact with the basement membrane of seminiferous tubules. Their cytoplasm contained oval mitochondria. They contained oval nuclei with peripheral heterochromatin (Figure 5A). Spermatogonia B were seen resting on the basement membrane of seminiferous tubules. These cells were spherical in shape and their cytoplasm contained oval or rounded mitochondria. They had rounded euchromatic nuclei with large masses of heterochromatin along the inner layer of

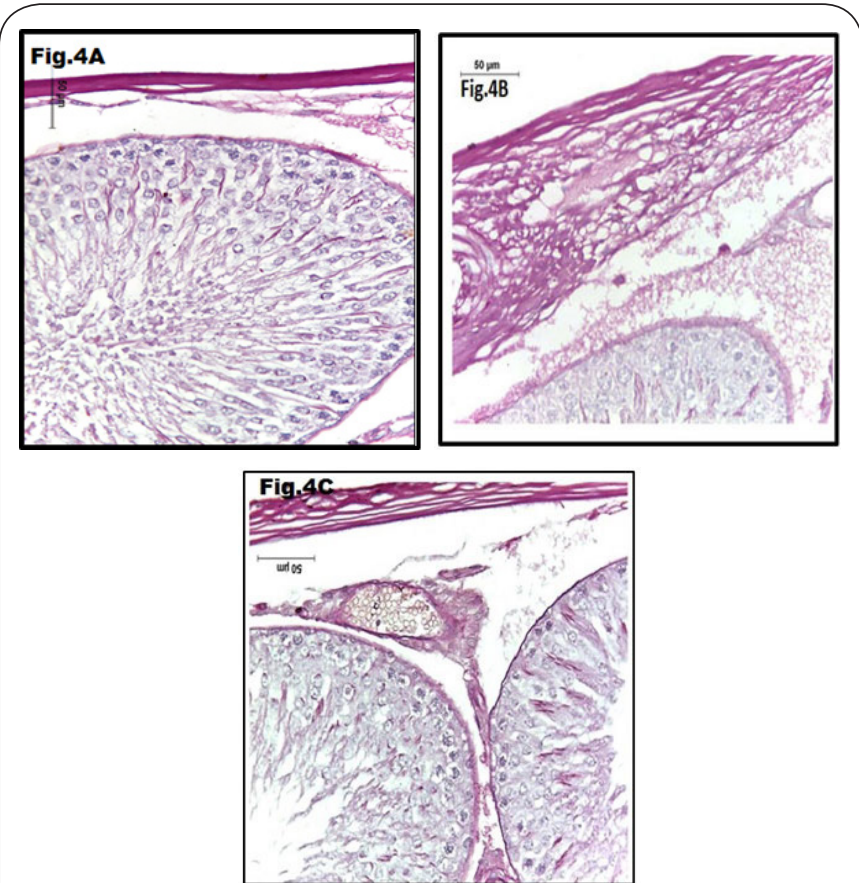

Figure 4. (A) A photomicrograph of transverse section of testis of adult albino rat of group A showing normal PAS positive reaction in the capsule, the basal lamina of seminiferous tubule and the spermatogenic cells.

(B) A photomicrograph of transverse section of testis of adult albino rat of group B showing mild PAS positive reaction in the capsule and in the basal lamina of seminiferous tubules and the spermatogenic cells.

(C) A photomicrograph of transverse section of testis of adult albino rat of group $\mathrm{C}$ showing the moderate PAS positive reaction in the capsule, the basal lamina of the seminiferous tubules and the spermatogenic cells. nuclear envelope. The primary spermatocytes were large cells present inner to the spermatogonia. Their cytoplasm contained small mitochondria. They were characterized by nearly rounded heterochromatic nuclei which had coarse clumps of heterochromtin (Figure 6A). The early spermatids appeared as polygonal cells. Their cytoplasm contained characteristic small mitochondria with clear matrix. The mitochondria were distributed at the periphery of the cells close to the plasma membrane. They had nearly rounded, central and euchromatic nuclei (Figure 7A). Spermatozoa were relatively elongated cells consisted of 3 main components head, neck and tail. The tail (Figure 8A) was subdivided into three pieces; the middle piece, the principal piece and the end piece in that order from the head. The middle piece contained central axoneme which composed of two central single microtubules and outer nine doublets. The central axoneme was surrounded by nine outer dense fibers arranged longitudinally around it. External to those core characteristic mitochondria with clear matrix and enlarged spaces between the cristae were arranged in a tightly packed helix encircling the outer dense fibers. Finally, these 


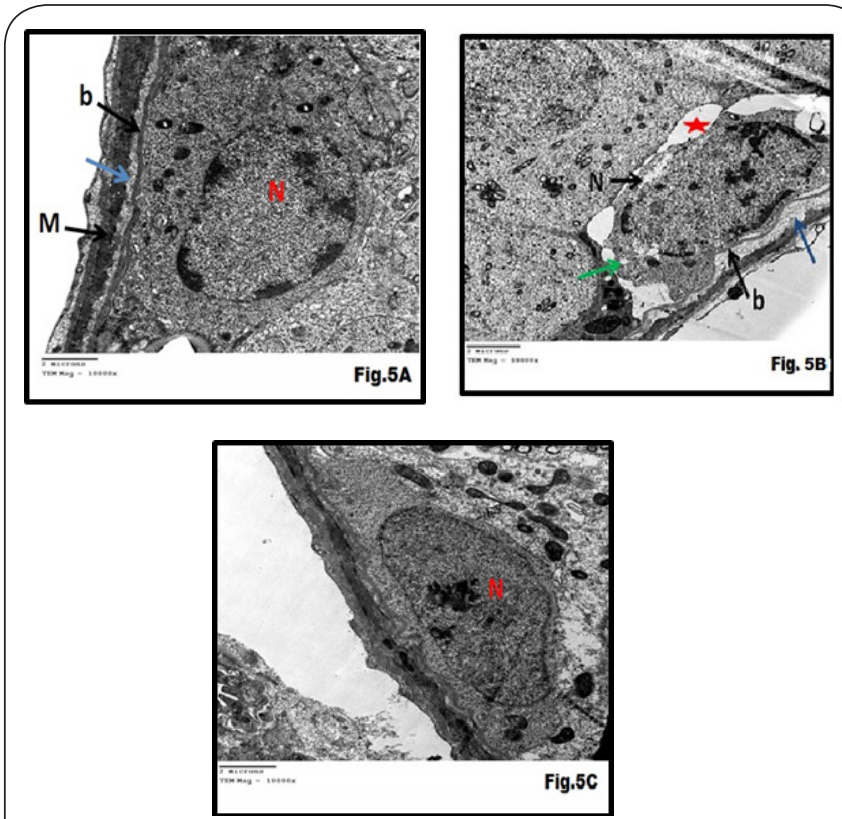

Figure 5. (A) Electron micrograph of the adult albino rat testis of group A showing that the basal lamina of the seminiferous tubule consists of: the basement membrane (b) and two cellular layers; myoid (M) and fibroblast layers. Notice the collagen fibers between the basement membrane and the myoid layer (blue arrow). Also, notice that spermatogonum A with its oval nucleus $(\mathrm{N})$ has a wide area of contact with the basement membrane.

(B) Electron micrograph of testis of adult albino rat group B showing irregularity of the basement membrane (b) with increased collagen fibers deposition (blue arrow) in the basement membrane. The spermatogonia A has cytoplasmic vacuolations (green arrow) and disrupted nuclear membrane (N). Notice the presence of wide intercellular spaces (red star). (C) Electron micrograph of testis of adult rat group C showing that the basal lamina appears less irregular with less deposition of collagen fibers as compared with that of group B. Notice the spermatogonum A with its oval nucleus $(\mathrm{N})$ appear nearly similar to that of the control.

structures were surrounded by residual cytoplasm and the plasmalemma. The principal piece consisted of the central core comprising the axoneme and the nine coarse fibers extending from the middle piece. This core was surrounded by an electron dense fibrous sheath. This fibrous sheath was formed of numerous semicircular ribs which became thickened at two opposite sides of the principal piece to form dorsal and ventral columns. Finally the fibrous sheath was surrounded by the plasmalemma. The end piece was composed only of the central axoneme surrounded by the plasmalemma.

\section{Group B}

Light microscopic examination of transverse sections of testes of group B showed that the testicular capsule was thick and irregular with congested dilated blood vessels. The spaces between the seminiferous tubules were wide and full with

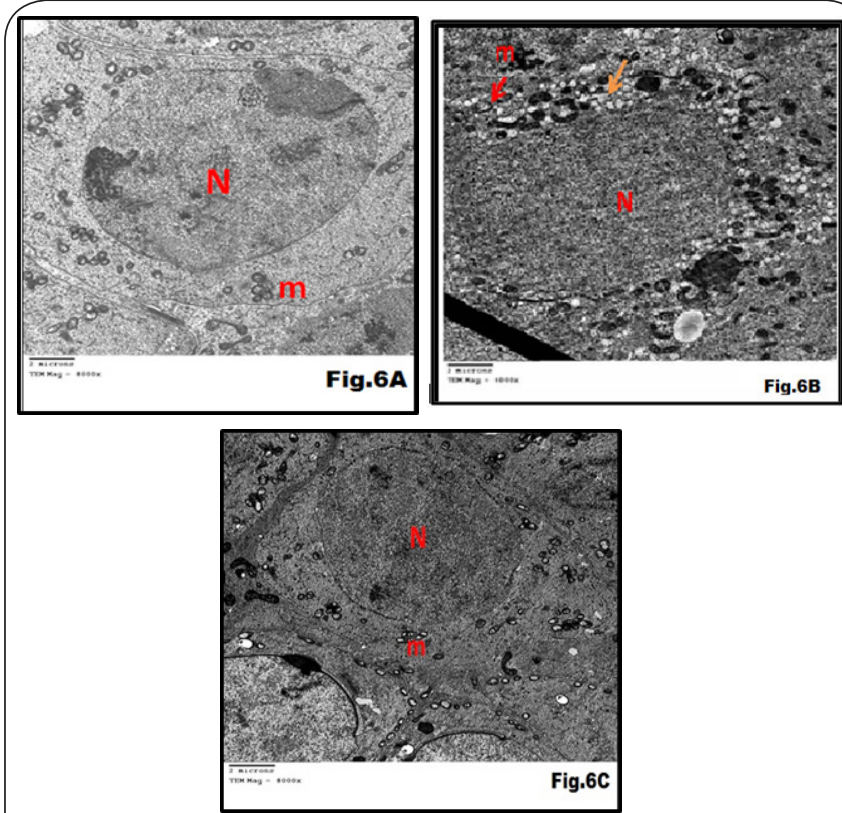

Figure 6. (A) Electron micrograph of adult albino rat testis of group Ashowing that the primary spermatocyte with its hetrochromatic nucleus $(\mathrm{N})$. Its cytoplasm contains small mitochondria $(\mathrm{m})$.

(B) Electron micrograph of testis of adult rat of group B showing that the cytoplasm of the primary spermatocyte has many small vacuolations(orange arrow) and degenerated mitochondria $(\mathrm{m})$. Notice that it has irregular nucleus $(\mathrm{N})$ with absence of hetrochromatin.

(C) Electron micrograph of the testis of adult albino rat group $\mathrm{C}$ showing that the primary spermatocyte has small mitochondria $(\mathrm{m})$ and heterochromatic nucleus $(\mathrm{N})$.

eosinophilic material (Figure 1B). The interstitial cells of leydig appeared dispersed (Figures 2B1 and 2B2). There were different degrees of affection of the seminiferous tubules ranging from moderate to severe deterioration. The basal lamina of the seminiferous tubules become distorted and detached in some areas. The spermatogenic cells sloughed into the interstitium. The spermatogenic cells appeared distorted. Sertoli cells were hardly detected. Most of the cells had vacuolated cytoplasm. Some of them had deeply stained pyknotic nuclei. Few spermatozoa were present in lumen of these tubules (Figures 2B1 and 2B2). Sections stained with Masson's trichrome stain showed marked increase in distribution of collagen fibers in the capsule (Figure 3B). Sections stained with Periodic Acid Schiff's stain (PAS) showed mild PAS positive reaction in the capsule, basal lamina and in the spermatogenic cells (Figure 4B).

Ultrastructural examination of the testes of group $B$ showed that the separation gap between the basement membrane and the myoid cell layer and the gap between the myoid cell layer and the fibroblast cell layer showed increased collagen fiber deposition (Figure 5B) as compared with that of the control (Figure 5A). The basal lamina of seminiferous tubules appeared irregular with the presence of intercellular 

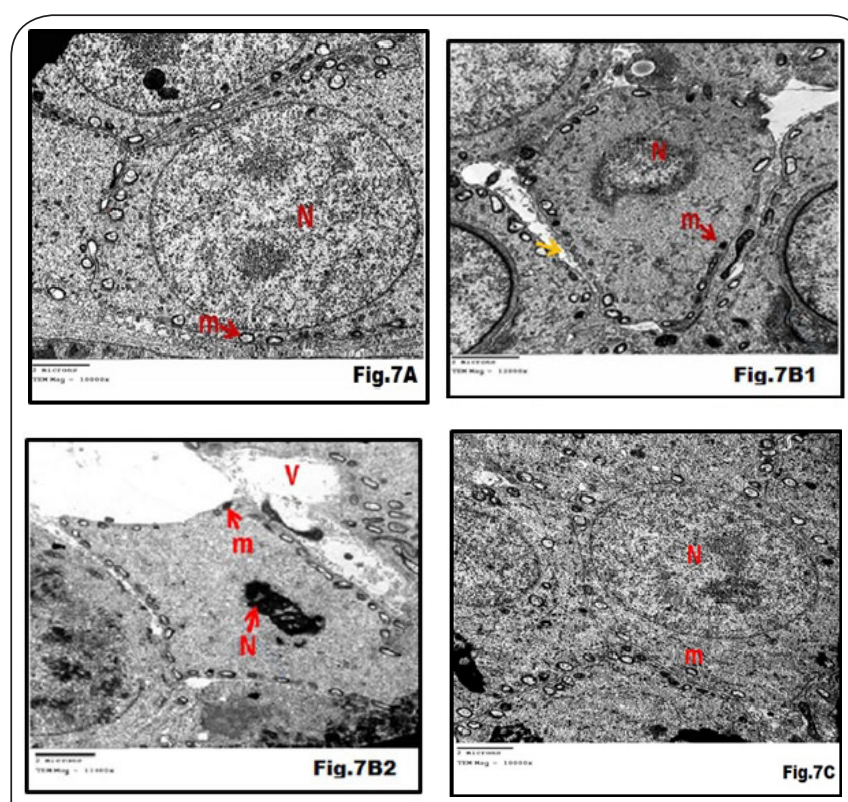

Figure 7. (A) Electron micrograph of adult albino rat testis of group A showing the earlyspermatid with its rounded heterochromatic nucleus $(\mathrm{N})$. Notice that its cytoplasm shows the peripheral arrangement of characteristic small mitochondria with clear matrix $(\mathrm{m})$.

(B1) Electron micrograph of testis of adult albino rat of group $B$ showing that the early spermatid has irregular outline (yellow arrow) with degenerated mitochondria (m) and shrunken irregular nucleus $(\mathrm{N})$.

(B2) Electron micrograph of testis of adult rat group B showing that the early spermatid vacuolated cytoplasm(V), has degenerated mitochondria (m) and shrunken irregular degenerated nucleus $(\mathrm{N})$.

(C) Electron micrograph of the testis of adult albino rat of group $\mathrm{C}$ showing the early spermatid with its characteristic mitochondria $(\mathrm{m})$ and rounded heterochromatic nucleus $(\mathrm{N})$.

spaces between the cells of seminiferous tubules (Figure 5B). Spermatogonia A revealed irregularity in their shape. Their cytoplasm showed vacuolations. Some mitochondria appeared degenerated. Their nuclear membranes disrupted in some areas (Figure 5B). The primary spermatocytes had ill -defined plasma membranes. Their cytoplasm contained small sized cytoplasmic vacuolations. Some mitochondria appeared degenerated. Their nuclei showed irregular nuclear envelope with absence of heterochromatin (Figure 6B) as compared with the control (Figure 6A). Some of the early spermatids were severely affected. The cells had irregular plasma membranes which were absent in some areas. Some mitochondria appeared degenerated. Some of the affected spermatids showed irregular, shrunken nuclei with ill-defined nuclear membranes (Figure 7B1). Other spermatids had high heterochromatic irregular small nuclei (Figure 7B2). The sperms revealed that most of them were markedly affected. Their detailed structures couldn't be recognized. The parts of the tail showed that they became electron opaque (Figure 8B).

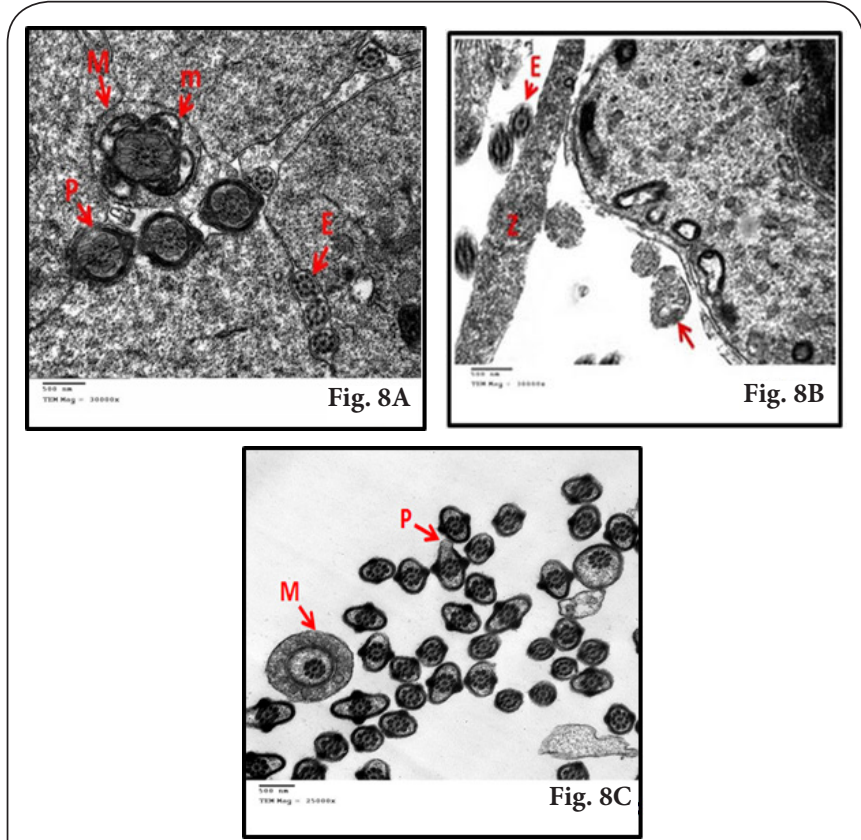

Figure 8. (A) Electron micrograph of adult albino rat testis of group A showing transverse sections of the different pieces of the tails of the spermatozoa. The middle piece (M) has characteristic arrangement of its mitochondria (m). Notice principle piece $(\mathrm{P})$ and end piece $(\mathrm{E})$.

(B) Electron micrograph of the testis of adult rat of group B showing that most of pieces of the tail of the sperm cannot be recognized (arrow). Notice that end pieces (E) have illdefined plasmalemma. Notice that the detailed structures of the longitudinal section of the sperm $(\mathrm{Z})$ cannot be recognized.

(C) Electron micrograph of the testisof adult albino rat group $\mathrm{C}$ showing that most of transverse sections of the tail of the sperms appear similar to that of group A but some pieces are affected. Notice the middle piece (M) has ill- defined mitochondria and the principal piece $(\mathrm{P})$ has disrupted plasmalemma.

\section{Group C}

Light microscopic examination of transverse sections of the testes of group $C$ showed that the testicular capsule had mild irregularity and thickness. The seminiferous tubules showed mild deterioration (Figures $\mathbf{1 C}$ and $\mathbf{2 C}$ ). The spaces between the seminiferous tubules (Figure 1C) appeared similar to that of the control (Figure 1A). There was no esinophilic material between seminiferous tubules. The interstitial tissue (Figure 2C) appeared nearly similar to the control (Figure 2A). The basal lamina of the seminiferous tubules (Figure 2C) appeared nearly similar to that of the control (Figure 2A). The spermatogenic cells (Figure $\mathbf{2 C}$ ) became easily recognized and were arranged in rows along the basal lamina of the seminiferous tubules nearly similar to that of the control group (Figure 2A). Most of the spermatogenic cells (Figure $\mathbf{2 C}$ ) appeared similar to that of the control (Figure 2A). Some cells had vacuolated cytoplasm and pyknotic or deeply stained nuclei (Figure 2C). 
Sections stained with Masson's trichrome stain showed that the distribution of collagen fibers in the capsule and basal lamina (Figure $3 C$ ) was nearly similar to that of the control (Figure 3A). Sections stained with Periodic Acid Schiff's stain (PAS) showed moderate PAS positive reaction in the capsule, basal lamina and in the spermatogenic cells (Figure $4 \mathrm{C}$ ).

Ultrastructural examination of the testes of group $C$ showed improvement in the structure of the basal lamina of the seminiferous tubules (Figure 5C) as compared with the group B (Figure 5B). The intercellular spaces between the spermatogonia decreased or absent. The spermatogonia cells showed that the cytoplasmic vacuolations were absent but some mitochondria showed degeneration (Figure $\mathbf{5 C}$ ). The primary spermatocytes showed that the plasma membrane had well-defined cell membrane, absence of cytoplasmic vacuolations and the mitochondria appeared similar to that of the control. Their nuclei were nearly rounded with clumps of heterochromatin (Figure 6C). The early spermatids (Figure 7C) were mildly affected. Their shapes were nearly polygonal, the mitochondria were not regularly arranged all around the periphery of the cells close to the plasma membrane and their nuclei appeared similar to that of the control (Figure 7A). Sperms revealed that they were mildly affected. Most of sperms appeared similar to the control. The middle pieces of few sperms showed that the mitochondria couldn't be detected. The principal piece of the tail in few sperms showed disruption of their plasma membrane (Figure $8 \mathrm{C}$ ).

\section{Morphometric results}

The mean epithelial height in the seminiferous tubules of group $A$, group $B$, group C and group D were (105.70 \pm 18.87 ), (77.07 \pm 14.69$),(91.38 \pm 16.18)$ and $(105.26 \pm 18.94)$ respectively (Table 1 and Graph 1). By applying one way ANOVA statistical analysis, these values revealed a highly significant difference $(\mathrm{P}<0.001)$ between the studied groups (Table 1$)$.

Post Hoc test investigated the significance between the individual groups (Table 1). It showed a highly significant decrease in group $B(P<0.001)$ and group $C(P=0.001)$ when compared with the group $A$. Also, it showed a highly significant decrease in group $B(P=0.001)$ and group $C(P<0.001)$ when compared with group $D$. On the other hand, it showed a highly significant increase in group $C(P=0.001)$ and group $D$

Table 1. The mean epithelial heights in the seminiferous tubules of studied groups.

\begin{tabular}{llllll}
\hline \multirow{2}{*}{ Groups } & \multicolumn{2}{l}{ Epithelial height } & \multicolumn{2}{l}{ One way ANOVA } \\
& Mean \pm SD & Range & F & P-value \\
\hline Group A & $105.70 \pm 18.87$ & $68.65-164.01$ & 21.068 & $<0.001$ \\
Group B & $77.07 \pm 14.69$ & $47.32-107.98$ & & \\
Group C & $91.38 \pm 16.18$ & $65.59-136.83$ & & \\
Group D & $105.26 \pm 18.94$ & $68.65-164.01$ & & \\
\hline Post Hoc Analysis: Tukey test & & & \\
\hline A vs B & A vs C & A vs D & B vs C & B vs D & C vs D \\
P $<0.001$ & $P=0.001$ & $P=0.916$ & $P=0.001$ & $P=0.001$ & $P<0.001$ \\
\hline
\end{tabular}

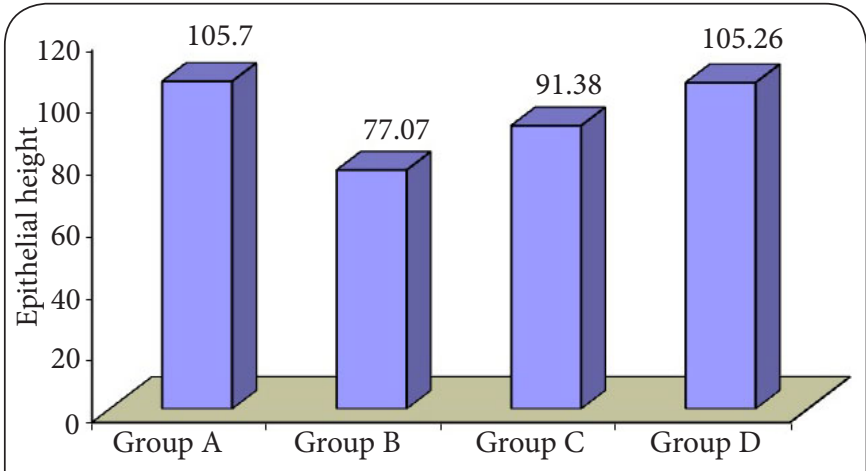

Graph 1. The mean epithelial heights in the seminiferous tubules of studied groups.

$(P=0.001)$ when compared with group $B$. However, there was insignificant difference between group A \& group D.

\section{Discussion}

In the present study, light microscopic examination of transverse sections of testes of (group B) showed testicular changes ranging from moderate to severe affection. Also, the morphometric results revealed decrease in the epithelial height of seminiferous tubules in this group as compared with the control. These might be due to degeneration to spermatogenic cells. These findings were in line with the study which observed that chronic exposure of adult male albino rats to noise stress (white band noise 6 hours for 30 days) induced a testicular histological changes in the form of a moderate reduction in the size of seminiferous tubules with focal degeneration and decrease of spermatogenic cells and diffuse hyperplasia of Leydig cells in the interstitium [22]. The present study showed that the basal lamina of the seminiferous tubules become distorted and detached in some areas. The spermatogenic cells sloughed into the interstitium. This was in agreement with a study which found that the basement membrane of the seminiferous tubules was broken and the germ cells sloughed into the interstitium in male albino rats exposed to $100 \mathrm{~dB}$ of noise daily one hour exposure for 60 days and 90 days [23].

The current study showed marked increase in distribution of collagen fibers in the capsule of testes of (group B). This finding might be due to disturbance in oxidant-antioxidant system. This suggestion was in line with a study which indicates that noise exposure results in ischemia and long-term hypoxia which lead to the formation of free radicals and lipid peroxidation [6]. Lipid peroxidation caused oxidative damage to proteins and nucleic acids and the end results of these reactions increased collagen and ground substance formation [24].

The present study showed that ultra-structural examination of spermatogonia A, primary spermatocytes, some of the early spermatids of testes of (group B) revealed variable degrees of degenerations. These results were agreed with a study 
that examined the effect of noise exposure (1, 6 and $12 \mathrm{~h})$ continuously on rat adrenal gland [25]. The authors observed that the mitochondria of the zonafasciculata showed matrix dilution and cristolysis after 1 and $12 \mathrm{~h}$ of noise stress. The zona reticularis exhibited areas of diluted cytoplasm, disarranged endoplasmic reticulum, membrane vestigia and some altered mitochondria at all exposure times examined [25]. Also, these results were in line with the results of the authors who examined the injurious effects of white noise $(100 \mathrm{~dB})$ on the hippocampus [26]. The authors found that the Pyramidal neurons of the noise exposed group showed different stages of degeneration as darkened irregular shrunken cell bodies of cells. The mitochondria were irregular and having disrupted cristae. Nuclear irregularities and extrusion of the nucleolus to the periphery were also detected [26].

The current work showed that ultra-structural examination of the sperms of testes of (group B) revealed that most of them were markedly affected. The abnormal ultra-structure of sperms might affect the fertility or even led to infertility. These results were in line with the results of a study that found that in chronic noise exposed rats there was maturation arrest in the germ cells due to reduced testosterone level and the epididymal sperms were agglutinated and the number of dead sperms was increased [27]. In addition, some authors mentioned that male infertility might be manifested by decrease in the amount of sperm cells and disorders in their mobility as well as structure. The causative agents might be chemical, ionizing radiation as well as stress [28].

The changes in the spermatogenic cells after noise exposure could be due to the stressful effects of noise which led to production of excessive reactive oxygen species (ROS). Some authors found that reactive oxygen species (ROS) played an important role in acute inflammation, endothelial destruction, increased vascular permeability and exudation of plasma resulting in tissue oedema [29]. During stress, the hypothalamic-pituitary-adrenal axis was activated, the glucocorticoid secretion increased and consequently, circulating testosterone level were decreased via glucocorticoid receptors in leydig cell [30]. There was maturation arrest in the germ cells due to reduced testosterone level. The leydig cells proliferation was likely to be a compensatory mechanism to increase testicular steroidogenesis trigged by testosterone insufficiency. The low testosterone production adversely affects the quality of ejaculates and subsequent fertility [30]. That noise led to production of excessive reactive oxygen species (ROS) [31]. Also, it was mentioned that noise led to direct oxidative DNA damage and activation of apoptosis [32].

The current work showed that light microscopic examination of transverse sections of adult albino rat testes exposed to noise and treated with black seed oil (group C) showed attenuated the testicular injury as compared with the group B. Also, the morphometric results revealed increased in the epithelial height of seminiferous tubules in this group as compared with that of the group B. These findings might be due to the antioxidant effect of NS oil on the testes. The present results were in line with a study that concluded that black seed oil had a protective and antioxidant effect on testicular, accessory sex gland functions in animals exposed to oxidative stress induced by hydrogen peroxide [33]. Also, these results are in line with a study that examined the protective effects of cool extraction of NS oil on testis against oxidative stress of carbon tetrachloride in male rats. In that study, it was found that NS extract had the ability to protect the testis against oxidative and histological damages induced by carbon tetrachloride, possibly through antioxidant effects of its bioactive compounds. However, this protection was dose dependant and whether the anti-oxidative action induced by NS oil as a result of a direct action or a result of indirect effects, e.g., including antioxidative enzymes cascade, the anti-oxidative action is not clear and should be subjectedfor for further investigation [34].

The present work showed that the distribution of collagen fibers in the capsule and basal lamina of group C was nearly similar to the control. This result agreed with the study which found that NS can prevent liver fibrosis and cirrhosis, suggesting that NS protects liver against fibrosis possibly through immunomodulator and antioxidant activities [35].

\section{Conclusion}

The present data strongly suggest a negative role for noise stress on the testes of the adult male albino rats. However, these results should be further assessed in human exposed to noise. Treatment with black seed or NS oil significantly attenuated the testicular injury by reducing inflammation, fibrosis and oxidative stress.

\section{Competing interests}

The authors declare that they have no competing interests.

Authors' contributions

\begin{tabular}{|l|c|c|c|}
\hline Authors' contributions & AFM & SMH & AM \\
\hline Research concept and design & $\checkmark$ & $\checkmark$ & $\checkmark$ \\
\hline Collection and/or assembly of data & $\checkmark$ & $\checkmark$ & $\checkmark$ \\
\hline Data analysis and interpretation & $\checkmark$ & $\checkmark$ & $\checkmark$ \\
\hline Writing the article & $\checkmark$ & $\checkmark$ & -- \\
\hline Critical revision of the article & $\checkmark$ & $\checkmark$ & -- \\
\hline Final approval of article & $\checkmark$ & $\checkmark$ & -- \\
\hline Statistical analysis & $\checkmark$ & $\checkmark$ & -- \\
\hline
\end{tabular}

Publication history

Editor: Paola Castrogiovanni, University of Catania, Italy. EIC: Gaetano Giuseppe Magro, University of Catania, Italy. Received: 05-Aug-2015 Final Revised: 25-Sep-2015

Accepted: 10-Oct-2015 Published: 20-Oct-2015

\section{References}

1. Jalali M, Hemadi M, Saki G and Sarkaki A. Study of spermatogenesis fetal testis exposed noise stress during and after natal period in rat. Pak J Biol Sci. 2013; 16:1010-5. I Article I PubMed

2. Monsefi M. A, Bahoddini A, Nazemi S and Dehghani G. A. Effects of noise 
exposure on the volume of adrenal gland and serum levels of cortisol in rat. Iran J. Med. Sci. 2006; 31:5-8. | Pdf

3. Ghanbari M, Mortazari S.B, Khavanin A and Khazaei M. Simultaneous effects of exposure to microwaves and noise on male rats sperm parameters and total antioxidant capacity. Health Scope. 2013; 1:180186.

4. Yildirim I, Kilinc M, Okur E, Inanc Tolun F, Kilic MA, Kurutas EB and Ekerbicer HC. The effects of noise on hearing and oxidative stress in textile workers. Ind Health. 2007; 45:743-9. | Article | PubMed

5. Pramanik $P$ and Biswas $S$. Traffic noise: a silent killer of male gamete of albino rats. Al Ameen J. Med. Sci. 2012; 5:82-89. I Pdf

6. Dehghani A, Ranjbarian M, Khavanin A, Rezazade $M$ and Vosooghi Z. Exposure to noise pollution and its effect on oxidant and antioxidant parameters in blood and liver tissue of rat. Zahedan. Journal of Research in Medical Sciences. 2013; 15:13-17. | Article

7. Gannouni N, Mhamdi A, Tebourbi O, El May M, Sakly M and Rhouma $K B$. Qualitative and quantitative assessment of noise at moderate intensities on extra-auditory system in adult rats. Noise Health. 2013; 15:406-11. | Article | PubMed

8. Tabish S. A. Complementary and Alternative Healthcare: Is it Evidencebased? Int. J. Health Sci. 2008; 2: 5-12. | Article

9. Ali BH and Blunden G. Pharmacological and toxicological properties of Nigella sativa. Phytother Res. 2003; 17:299-305. | Article | PubMed

10. Abdel-Fattah AM, Matsumoto $K$ and Watanabe $H$. Antinociceptive effects of Nigella sativa oil and its major component, thymoquinone, in mice. Eur J Pharmacol. 2000; 400:89-97. | Article | PubMed

11. Mansour MA, Nagi MN, El-Khatib AS and Al-Bekairi AM. Effects of thymoquinone on antioxidant enzyme activities, lipid peroxidation and DT-diaphorase in different tissues of mice: a possible mechanism of action. Cell Biochem Funct. 2002; 20:143-51. | Article | PubMed

12. Bayrak O, Bavbek N, Karatas OF, Bayrak R, Catal F, Cimentepe E, Akbas A, Yildirim E, Unal D and Akcay A. Nigella sativa protects against ischaemia/ reperfusion injury in rat kidneys. Nephrol Dial Transplant. 2008; 23:2206-12. | Article | PubMed

13. Yakoot $M$ and Salem A. Efficacy and safety of a multiherbal formula with vitamin C and zinc (Immumax) in the management of the common cold. Int J Gen Med. 2011; 4:45-51. | Article | PubMed Abstract | PubMed Full Text

14. Shohayeb $M$ and Halawani E. Comparative antimicrobial activity of some active constituents of N. sativa L. World Applied Sciences J. 2012; 20:182-189. | Pdf

15. Ramsey JD and Flanagan RJ. The role of the laboratory in the investigation of solvent abuse. Hum Toxicol. 1982; 1:299-311. | Article | PubMed

16. Mahmoud MR, El-Abhar HS and Saleh S. The effect of Nigella sativa oil against the liver damage induced by Schistosoma mansoni infection in mice. J Ethnopharmacol. 2002; 79:1-11. | Article | PubMed

17. Buyukozturk S, Gelincik A, Ozseker F, Genc S, Savran FO, Kiran B, Yillar G, Erden S, Aydin F, Colakoglu B, Dal M, Ozer H and Bilir A. Nigella sativa (black seed) oil does not affect the T-helper 1 and T-helper 2 type cytokine production from splenic mononuclear cells in allergen sensitized mice. J Ethnopharmacol. 2005; 100:295-8. | Article | PubMed

18. Kieranan J. A. "Histological \&Histochemical Methods". $3^{\text {rd }}$ ed., Oxoford University Press, London, New York, New Delhi: 2001; 103-130.

19. Bancroft J. D and Steven S. A. "An Introduction to Embryology". $5^{\text {th }}$ ed., Saunders, Coblege, Philadelphia, New York, Chicago, San Francisco. 1996; 524-526.

20. Bancroft J.D and Gamble M. Theory and Practice of Histological Techniques. 6 $^{\text {th }}$ ed. Churchill Livingstone, London. 2008; 340-348. | Book

21. Mould R.F. Introductory Medical Statistics. $2^{\text {nd }}$ ed., Adam Hilger, Bristol and Philadelphia: 1989; 17-26. | Book

22. Diab A. A, Hendawy A, Asala A. K, Ibrahim S. S and Hassan M. A. Effect of Noise Stress on pituitary gonadal axis in albino rats. J. Am. Sci. 2012; 8:198-202. | Pdf

23. Swami CG, Ramanathan J and Charan Jeganath C. Noise exposure effect on testicular histology, morphology and on male steroidogenic hormone. Malays J Med Sci. 2007; 14:28-35. | PubMed Abstract | PubMed Full Text

24. Bacon BR and Britton RS. Hepatic injury in chronic iron overload. Role of lipid peroxidation. Chem Biol Interact. 1989; 70:183-226. | Article | PubMed

25. Pellegrini A, Soldani P, Gesi M, Lenzi P, Natale G and Paparelli A. Effect of varying noise stress duration on rat adrenal gland: an ultrastructural study. Tissue Cell. 1997; 29:597-602. I Article I PubMed

26. Abousetta A, Makhlouf N.A and El-Beshbishy R.A. The effects of concomitant Ginkgo intake on noise induced Hippocampus injury. Possible auditory clinical correlate. Egyptian Journal of Ear, Nose, Throat and Allied Sciences. 2014; 15:231-239. | Article

27. Chandrasekhar $\mathrm{G}$. The effect of noise induced stress on the reproductive endocrine gland of rats. Thesis Medical University and Research Chennai, India. 2002. I Article

28. Wdowiak $A$, Wdowiak $L$ and Wiktor $H$. Evaluation of the effect of using mobile phones on male fertility. Ann Agric Environ Med. 2007; 14:16972. | Article | PubMed

29. Zhitkevich TI, Bokut TB and Netukova NI. [Effect of low-intensity electromagnetic fields of industrial frequency on the ultrastructure and proliferative activity of rat's thymus cells]. Radiats Biol Radioecol. 2001; 41:403-7. | Article | PubMed

30. Mylchreest E, Sar M, Wallace DG and Foster PM. Fetal testosterone insufficiency and abnormal proliferation of Leydig cells and gonocytes in rats exposed to di(n-butyl) phthalate. Reprod Toxicol. 2002; 16:19-28. | Article | PubMed

31. Manikandan S, Padma MK, Srikumar R, Jeya Parthasarathy N, Muthuvel A and Sheela Devi R. Effects of chronic noise stress on spatial memory of rats in relation to neuronal dendritic alteration and free radicalimbalance in hippocampus and medial prefrontal cortex. Neurosci Lett. 2006; 399:17-22. | Article | PubMed

32. Dharini S. Effect of Acoruscalamus Linn and its active principle on noise stress-induced changes on immune system. Int. J. Biomed. Adv. Res. 2012; 3:494-501. | Article

33. Tawfeek F.K.H, Ahmed S.M and Kakel S.J. Effect of Nigella Sativa oil treatment on the sex organs and sperm characters in rats exposed to hydrogen peroxide. Mesopotamia J. of Agric. 2006; 34. I Pdf

34. Danladi J, Ahmed S.A, Akpulu S.P, Owolagba G.K, Iduh M.U and Mairiga A.A. Protective effect of cool extraction of black seed (Nigella Sativa) oil against CCl4-Induced oxidative damages in Wistar rats testis. 2013; 5:68-74. | Pdf

35. Turkdogan MK, Agaoglu Z, Yener Z, Sekeroglu R, Akkan HA and Avci ME. The role of antioxidant vitamins ( $C$ and $E$ ), selenium and Nigella sativa in the prevention of liver fibrosis and cirrhosis in rabbits: new hopes. Dtsch Tierarzt/ Wochenschr. 2001; 108:71-3. | Article | PubMed

Citation:

Mohamed AF, Hanafy SM and Mahmoud A. The possible protective effect of black seed (Nigella Sativa) oil on the testes of adult male albino rat exposed to noise. J Histol Histopathol. 2015; 2:21.

http://dx.doi.org/10.7243/2055-091X-2-21 